\title{
A test for artifactual effects in an attitude similarity/interpersonal attraction study
}

\author{
HUGH McGINLEY \\ University of Wyoming, Laramie, Wyoming 82701
}

\begin{abstract}
Both a direct and indirect measure were used in order to assess subjects' awareness of attitude similarity or dissimilarity between themselves and strangers. Although there was an attitude similarity/interpersonal attraction effect, there were no significant differences between the aware and unaware subjects either in their attraction toward the strangers or in the correctness of their recall of the strangers' attitudes.
\end{abstract}

During the last score of years, there has been a renewed interest in the effects of the environment and the procedures of psychological experiments on their outcomes (Adair, 1973; Barber, 1976; Rosenthal \& Rosnow, 1969).

Page (1969; Page \& Scheidt, 1971), in his inquiry into the conditioning of meaning and attitudes, has presented evidence suggesting that the demand characteristics of various landmark studies seem to account for the "conditioning of attitudes." Page's usual procedure for identifying demand characteristic effects is to ask subjects questions about experimental procedures and about the experimenter's expectancies in a postexperimental questionnaire. The questions vary from the indirect to the direct. In direct questioning, for instance, the subjects are told about the pertinent contingencies (contingency awareness), or the relationship between these contingencies and the dependent measure is explained and then the subjects are asked if they were aware of the relationship when they completed the dependent measure (demand awareness). Page typically finds that subjects who respond to the experimental manipulations in a manner that is consistent with a conditioning-reinforcement point of view also indicate, by their answers to the postexperimental questionnaire, that they know how they were expected to respond. The essence of Page's work seems to be to caution investigators to test for possible demand characteristics in their investigatory procedures.

In response to Page's (1969) caution, McGinley and Reiner (1979) studied the possible effects of contingency awareness in an attitude similarity/interpersonal attraction study. The results of this study and those by Lamberth and Byrne (1971) led McGinley and Reiner to the conclusion that there is a significant, positive relationship between attitude similarity and interpersonal attraction that is not potentially accounted for by contingency awareness. However, given the importance of not misexplaining empirically derived effects, Page's caution, as it applies to similarity-attraction effects, warrants further consideration. The present study represents a part of this consideration by employing a longer, and possibly a more sensitive, awareness questionnaire and by using an experimental procedure that, intuitively, should lead to a clearer separation of subjects who are judged to be contingency aware from those who are not so judged.

The postexperimental questionnaire used by Lamberth and Byrne (1971) consisted of two items: "What do you think the experiment was about?" and "What was the hypothesis [of the experiment] ?" These questions were to assess if subjects were aware of the similarity and dissimilarity of attitudes between themselves and strangers whose attitude questionnaires they had perused, and, if such awareness was apparent, did it influence the subjects' ratings of the strangers on the interpersonal judgment scale (Byrne, 1971)? In comparison with Page's awareness questionnaire (e.g., Page, 1969), the questionnaire used by Lamberth and Byrne was brief and indirect.

McGinley and Reiner (1979) used an 11-item awareness questionnaire that included items that were relatively suggestive, for example: "How do you think the experimenter expected you to rate the person whose attitude questionnaire you studied?" and "Do you think the experimenter expected you to respond in a consistent (positive or negative, for example) direction when you judged the person's intelligence, morality, etc.? If so, in what direction? Why?" Even though this questionnaire probed awareness more than the questionnaire used by Lamberth and Byrne (1971), it was not as explicit as the questionnaire used by Page (1969).

The awareness questionnaire that was used in the present study was similar to that used by McGinley and Reiner (1979) but included an additional three items that were concerned with how the subjects went about projecting how the strangers would fill out an interest inventory and why they were asked to recall how the strangers had marked their attitude surveys. It was thought that the questions about the subjects' projections of how the strangers would answer the interest inventory items would result in a verbalization of their attitude similarity or dissimilarity. The questions were: "Why did the experimenter ask you to mark how you felt the person would fill out the interest inventory?" 
and "Did you fill out the interest inventory for the person as to how you thought the experimenter wanted you to fill it out or as to how you thought the person would fill it out?" Additionally, it was thought that the subjects' accuracy of recall of how the strangers had responded to the attitude survey would lend insight into their awareness of the attitude similarity or dissimilarity between themselves and the strangers. Specifically, aware subjects could rely on a "set" of "similar to me" or "dissimilar to me" when "recalling" how the strangers had responded to the attitude items and, therefore, might have better recall than the unaware subjects.

\section{METHOD}

Subjects

The subjects were 94 female and 89 male students who were enrolled in freshman- and sophomore-level psychology classes. The participation was during the 1st month of the fall semester. All subjects volunteered to participate. No class credit was given.

\section{Procedure}

In their respective classes, the subjects were asked to complete a 20-item attitude survey consisting of one eight-interval scale per item. The survey, they were told, had been filled out routinely by students during the preceding 4 years. The experimenter asked that the subjects identify themselves so that the survey could be returned to them at a later date. Of the students, 95\% chose to complete the survey, and, of these, $95 \%$ also identified themselves. The content of the survey ranged from items dealing with the use of drugs to items concerned with governmental policy.

Two weeks later, the experimenter returned to the class and handed out packets that contained (1) a copy of the 20-item attitude survey that had been filled out by a person of the same sex as the subject, (2) the interpersonal judgment scale, (3) the UK-19 version of the A-B Scale (Seidman, 1972), which was referred to as the "interest inventory" in the study, (4) a blank copy of the 20-item attitude survey, (5) a 14-item awareness questionnaire, and (6) the 20 -item attitude survey that had been completed by the subject previously. Unknown to the subjects, the attitude survey of the strangers had been manipulated to be $90 \%, 50 \%$, or $10 \%$ similar to their own attitude surveys.

The items in the packet were ordered, and the subjects were asked to remove and replace the items when requested. The first item, the copy of another person's attitude survey, was removed from the packet and perused for $4 \mathrm{~min}$ so that an impression of the stranger could be formed. The survey was then returned to the packet, and the interpersonal judgment scale was removed and completed. The subjects were told that this was a standardized form on which they were to make judgments about the strangers. The subjects then were asked to fill out the interest inventory as they thought the strangers would answer the items. Next, the subjects were asked to mark the blank copy of the 20 -item attitude survey in the way that they remembered the strangers had marked it. The final form to be completed was the 14-item awareness questionnaire. Following the completion of this questionnaire, the subjects removed their own attitude surveys and the experimenter gave feedback information about each item, including information about attitudinal changes of students over a 4-year period.

\section{Scoring the Data}

The "liking" and "working together" items of the interpersonal judgment scale were summed in order to create a measure of interpersonal attraction. Theoretically, the attraction scores could range from a value of 2 to a value of 14 . The strangers' attitude surveys were compared with the subjects' recall of how the strangers had answered the items, and difference scores were computed. The scoring procedure used absolute value difference scores for each item, and then the scores were summed. Theoretically, the recall scores could range from 0 to 140. The awareness questionnaires were read by two judges who assessed whether the subjects' responses indicated contingency or demand awareness. Consistent with the discussion presented by McGinley and Layton (1973), subjects who were scored as demand aware were considered to be contingency aware. In those cases in which there was no agreement between judges, a third judge assessed the subject's awareness and the majority judgment was used. The coefficient of agreement between the initial judges was .84 .

\section{Analyses}

The two general analyses were by analysis of variance with unequal Ns. The factors were sex of the subject, proportion of attitude similarity $(.90, .50$, and .10$)$, and the judged contingency awareness of the subject (aware, unaware). Analyses were conducted for both the interpersonal judgment scale data and the correctness of recall data.

\section{RESULTS AND DISCUSSION}

Fifty-nine of the 183 subjects were judged to be contingency aware (36\%). The number of subjects from each of the attitude similarity conditions who were judged as aware out of the total number of subjects in each condition were $18 / 60,19 / 60$, and $22 / 58$, respectively, for the $90 \%, 50 \%$, and $10 \%$ attitude similarity conditions. There was no significant difference between the number of subjects from each condition who were judged contingency aware.

The analysis for the attraction data revealed only an attitude similarity effect $[\mathrm{F}(1,171)=43.65, \mathrm{p}<.005]$. The $F$ values for the sex and awareness factors were 1.90 and .71 , respectively. The interaction of most importance to the thesis of the project was the Attitude Similarity by Awareness interaction. Neither the $F$ value for this interaction $[F(2,171)=1.02]$ nor those for any of the other interactions reached significance. The respective means for the attitude similarities were $10.17,6.98$, and 6.65 for the proportions of $.90, .50$, and .10 . The .90 proportion condition led to significantly greater attraction than did either of the other two conditions, and there was no significant difference between the .50 and .10 proportion conditions.

These results do not suggest that the effect of attitude similarity on interpersonal attraction can be accounted for solely on the basis of the subjects' awareness of the similarity or dissimilarity of attitudes between themselves and the strangers. That is, both judged-aware and judgedunaware subjects showed the attitude similarity effect, but there was no significant difference between the groups.

The analysis of the recall data revealed no significant differences. All $\mathrm{F}$ values except that for awareness were less than 1 . The $\mathrm{F}$ value for the awareness factor was $1.44(\mathrm{df}=1,171)$. The recall scores for the $90 \%, 50 \%$, and $10 \%$ attitude similarity conditions were, respectively, 
$14.33,13.87$, and 11.91 for the judged-aware subjects and $12.78,14.11$, and 14.86 for subjects who were not judged to be aware. These results suggest that judgedaware subjects did not use their awareness of the strangers' attitude similarity to their advantage when recalling how the strangers had answered the attitude survey. On the other hand, one might speculate that although all of the subjects had attended well to the task of assimilating information about the strangers, only $36 \%$ of them referenced the information against their own attitudes in such a manner as to appear to be verbally aware of the attitude similarity and dissimilarity between themselves and the strangers. Also, it is possible that the contingency-aware subjects demonstrated no obvious superiority in their recall because most of the subjects had learned the strangers' responses quite well and there simply was not enough variation to differentiate the recall scores of judged-aware and judged-unaware subjects; that is, there was a ceiling effect.

Taken in their totality, the results of the study are consistent with those found by Lamberth and Byrne (1971) and by McGinley and Reiner (1979). The ubiquitous finding that a subject's interpersonal attraction toward a stranger is a direct function of the proportion of attitude similarity between the subject and the stranger is seemingly not simply an artifact based on demand characteristics.

\section{REFERENCES}

AdaIr, J. G. The human subject: The social psychology of the psychological experiment. Boston: Little Brown, 1973.

BARBER, T. X. Pitfalls in human research: Ten pivotal points. New York: Pergamon Press, 1976.

Byrne, D. The attraction paradigm. New York: Academic Press, 1971.

LAmberth, J., \& Byrne, D. Similarity-attraction or demand characteristics? Personality: An International Journal, 1971, 2, 77-91.

McGinley, H., \& Layton, B. Conditioning of evaluative meaning without contingency or demand awareness. Journal of General Psychology, 1973, 89, 81-90.

McGinley, H., \& Reiner, M. Contingency awareness and interpersonal attraction. Bulletin of the Psychonomic Society, 1979, 13, 175-178.

PAGE, M. M. Social psychology of a classical conditioning of attitude experiment. Journal of Personality and Social Psychology, 1969, 11, 177-186.

PAge, M. M., \& Scheidt, R. J. The elusive weapons effect: Demand awareness, evaluation apprehension, and slightly sophisticated subjects. Journal of Personality and Social Psychology, 1971, 20, 304-318.

Rosenthal, R., \& Rosnow, R. L. Artifact in behavioral research. New York: Academic Press, 1969.

Seidman, E. Which AB scale? Journal of Nervous and Mental Disease, 1972, 155, 105-109.

(Received for publication June 21, 1980.) 